\title{
Pregnancy in parents both with renal transplants
}

\author{
K K Nanayakkara ${ }^{1}$, A B Samarakoon ${ }^{1}$, B H Perera $^{1}$, C D Nanayakkara ${ }^{2}$ \\ Sri Lanka Journal of Obstetrics and Gynaecology 2010; 32: 44-46
}

\begin{abstract}
The antenatal management of a mother who received a kidney transplant at the tender age of 14 years and continually on immunosuppressive medication, married to a person who himself is a kidney transplant recipient on immunosuppressive medication, is exemplified in this case report. The effects of her medication during pregnancy, with her antenatal management and delivery are illustrated. The neonatal management of the baby and the medicinal effects on breast feeding and contraception is discussed.
\end{abstract}

Key words: Kidney transplant, pregnancy, antenatal management.

\section{Introduction}

The rapid turnover at the Renal Transplant Unit, Teaching Hospital Kandy, Sri Lanka, has resulted in many young women with end-stage renal failure receiving renal transplantations. Their ability to conceive without assisted reproductive techniques has been curiously observed for many years. The antenatal management of a mother who received a kidney transplant at the tender age of 14 years and continually on immunosuppressive medication, married to a person who himself is a kidney transplant recipient on immunosuppressive medication, is depicted and the potential fetal effects are deliberated.

\section{Case Report}

Ms. FR, detected with end-stage renal failure since 2001 received a live donor kidney transplant, from her cousin brother, in March 2002, at the age of 14 years. The transplant was successful and the graft remains stable. She is married to Mr. AAMN, 28 years, who also was detected with end-stage renal failure from the age of 24 years. He had received a live donor kidney transplant in April 2006, also from a cousin

\footnotetext{
${ }^{1}$ Department of Obstetrics and Gynaecology, Teaching Hospital, Kandy, Sri Lanka.

${ }^{2}$ Faculty of Dental Sciences, Peradeniya, Sri Lanka. Correspondence: K. K. Nanayakkara

E-mail: kalingananayakkara@yahoo.com
}

brother. In his case too, the transplant was successful and the graft remains stable. The Consultant Nephrologist had been consulted in pre-marriage counselling, and much to their delight, their childbearing ability had been sanctioned, after continual clinical and biochemical investigations.

Women are usually advised to wait at least 1 year after living related donor transplantation and 2 years after cadaver transplantation before conceiving. Ms. FR married seven years after her living related donor transplantation and conceived one year after marriage without assisted reproductive techniques. By waiting for the recommended time after transplantation to become pregnant, she has passed the peak time of risk for cytomegalovirus infection which is the most frequent cause of viral infection post-transplantation. Women who are not rubella immune should receive the rubella vaccine before transplantation, because live virus vaccines are contraindicated posttransplantation ${ }^{1}$. This had been adhered to, in her case.

\section{Medication during pregnancy}

The immunosuppressive medication taken by Ms. FR during her pregnancy and their fetal effects are listed below:

1. Prednisolone - Although prednisolone can cross the placenta the maternal- to cord-blood ratios are approximately 10:12. Therefore complications such as increased risk for cleft lip $(\mathrm{OR}=6.55 ; \mathrm{p}=0.015)$ 3 and fetal growth restriction 4 are unlikely if the dose of prednisone has been decreased to below $15 \mathrm{mg}$ daily ${ }^{5}$. Ms. FR who was on a daily dose of $7.5 \mathrm{mg}$.

2. Azathioprine - She was on a daily dose of $50 \mathrm{mg}$. Although $64-93 \%$ of azathioprine administered to mothers appears in fetal blood as inactive metabolites, the immature fetal liver lacks the enzyme inosinate pyrophosphorylase needed for conversion to its active metabolite, 6mercaptopurine, and the fetus is relatively protected from the effects of the drug .

3. Cyclosporin - She was on a daily dose of $50 \mathrm{mg}$. Cyclosporine crosses the placenta and the fetal levels of this drug may range between 30 and $64 \%$ 
of the maternal plasma concentration ${ }^{7}$. By literature the overall odds ratio for congenital malformations, with cyclosporine, of 3.47 (CI 0.86-14.4) was not statistically significant. However, the prevalence of low birth weight was statistically significant with an odds ratio of 1.59 (CI 1.05-2.40) ${ }^{8}$. A low birth weight baby was observed in this patient aided also by the steroids taken by her.

\section{Male kidney recipients}

It is also of note that in 195 pregnancies fathered by male kidney recipients, the pattern of pregnancy outcomes resembled that of the general population'.

\section{Antenatal history}

She was seen more frequently than the others in the antenatal clinic and always assessed by the consultant obstetrician with constant attention to renal function tests and urinary tract infection. Of the noted antenatal complications after renal transplant of hypertension ${ }^{10}$, pre-eclampsia, impaired renal function, pre-term labour $(19-45 \%)^{11}$ and fetal growth restriction (ranging from 13-25\%) ${ }^{11}$. only the last complication was detected in this patient by serial ultrasound examinations. Low birth weight infants $(38 \%)$ among female transplant recipients is significantly higher than that in the general population ${ }^{9}$ as revealed by the birth weight at delivery. Urinary tract infections, the most common bacterial infections that occur in up to $40 \%$ of pregnant transplant recipients was detected twice in this patient and warranted a 10-day course of oral antibiotics.

\section{Delivery}

An elective caesarean section was performed at the gestation of 38 weeks, taking into consideration the fetal growth restriction detected by serial ultrasound examinations. This was performed through a Pfannenstiel incision taking special care of the implanted kidney in the right iliac fossa. The baby with a birth weight of $2230 \mathrm{~g}$ was delivered and subsequently observed in the special care baby unit for two days and discharged without any of the complications listed below.

\section{Neonatal complications}

None of the established neonatal complications, such as asphyxia, physiological jaundice, disseminated intravascular coagulation, thrombocytopenia, intracerebral haemorrhage, hypoglycaemia and necrotizing enterocolitis, was seen in this neonate.

\section{Breast feeding}

Breastfeeding is discouraged for patients taking any immunosuppressive drugs. Cyclosporin measurement in maternal blood and breast milk revealed a mean breast milk/maternal blood level ratio of 0.8412 . These levels can be toxic to a newborn as can azathioprine.

\section{Contraception}

A low dose oestrogen-progesterone oral contraceptive preparation was advised. The risk of infection from the use of intrauterine devices (IUD) is increased in immunocompromised patients. Also the efficacy of IUDs may be reduced because of the antiinflammatory properties of immunosuppressive agents.

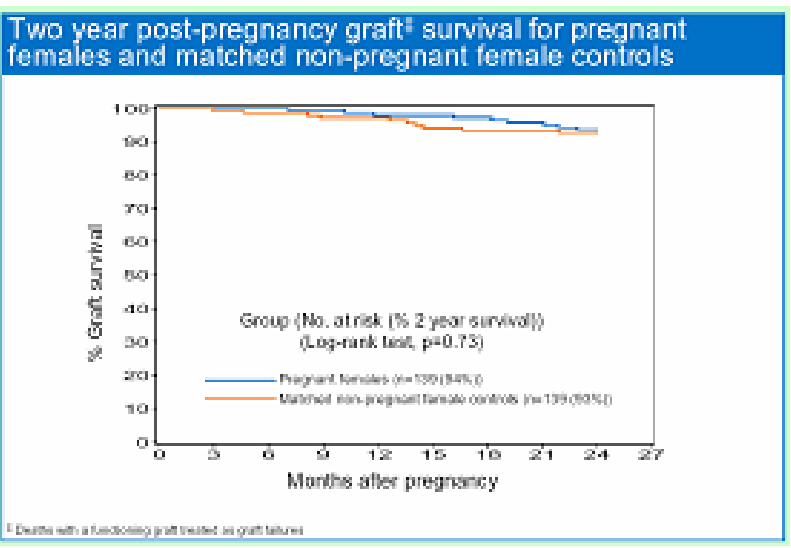

\section{Long-term sequelae}

Although a reduction in graft survival rates is seen over time in all transplant patients, no significant difference is seen in two year graft survival rates between pregnant females and non-pregnant matched female controls ${ }^{13}$.

\section{Discussion}

Child-bearing for women with end-stage renal failure, which seemed impossible some years ago, now emerge as a viable alternative with the establishment of renal transplant units in major hospitals in this country. There is only a minimal difference in the twoyear 'graft survival' rates between pregnant females and matched non-pregnant females, following renal transplantation. This significant detail would be most welcome for women with end-stage renal failure, to conceive and deliver normal babies, after kidney transplantation, and as in this patient, without assisted reproductive techniques.

\section{References}

1. Hou S. Pregnancy in chronic renal insufficiency and end stage renal disease. Am J Kidney Dis 1999; 33: 235-52. 
2. Beitins IZ, Bayard F, Ances IG, et al. The transplacental passage of prednisone and prednisolone in pregnancy near term. J Pediatr 1972; 81: 936-45.

3. Rodriguez-Panilla E, Martinez-Frias ML. Corticosteroids during pregnancy and oral clefts: A case-control study. Teratology 1998; 58: 2-5.

4. Fitzsimons $\mathrm{R}$ et al. Outcome of pregnancy in women requiring corticosteroids for severe asthma. J Allergy Clin Immunol 1986; 78: 349-53.

5. Penn I, Makowski EL, Harris P. Parenthood following renal transplantation. Kidney Int 1980; 18: 221-3.

6. Sarikoski S, Seppala M. Immunosuppression during pregnancy: Transmission of azathioprine and its metabolites from the mother to the fetus. Am J Obstet Gynecol 1973; 115: 1100.

7. Ostensen M. Treatment with immunosuppressive and disease modifying drugs during pregnancy and lactation. American Journal of Reproductive Immunology 1992; 28: 148-52.
8. Bar-Oz B, Ma J, Tsao S, Hackman R, Zamin M, Einarson TR, Koren GL. The effects of cyclosporine therapy on pregnancy outcome in organ transplanted women: A metaanalytical review. Teratology 1999; 59: 440.

9. Armenti et al. National Transplantation Pregnancy Registry, Thomas Jefferson University Hospital in Philadelphia (1992).

10. Muirhead N, Sabharwal AR, Rieder MJ, Lazarvotis AI, Hollomby DJ. The outcome of pregnancy following a renal transplantation - the experience of a single center. Transplantation 1992; 54(3): 429-32.

11. Penn I, Matowski EL, Harris P. Kidney Int 1980; 18: 221.

12. Munoz-Flores-Thiagaralan KD, Easterling T, Davis C, Bond EF. Breast feeding by a cyclosporine-treated mother. Obstet Gynecol 2001; 97: 816-8.

13. Sibanda et al. UK Transplant Pregnancy Registry, University of Newcastle upon Tyne (2002). 